\title{
Extracellular Dopamine in the Medial Preoptic Area: Implications for Sexual Motivation and Hormonal Control of Copulation
}

\author{
Elaine M. Hull, Jianfang Du, Daniel S. Lorrain, and Leslie Matuszewich \\ Department of Psychology, State University of New York at Buffalo, Buffalo, New York 14260
}

\begin{abstract}
Dopamine (DA) activity in the medial preoptic area (MPOA) contributes to the control of male rat sexual behavior. We tested (1) whether extracellular DA increases during precopulatory exposure to an estrous female and during copulation, (2) whether exposure to another male increases extracellular DA, (3) whether motor activity during copulation accounts for increased DA levels, and (4) whether concurrent or recent testosterone influences DA levels or copulation in castrates. Extracellular DA and its metabolites in male rats' MPOA were measured using microdialysis. DA levels increased during precopulatory exposure to the female in all animals that subsequently copulated; this included all intact animals, all testosterone-treated castrates, and 9 of 141 -week castrates treated with oil vehicle. DA levels did not increase in any animal that subsequently failed to copulate, including the remaining 1-week, and all 2-week, vehicle-treated castrates. When the barrier was removed and the animals were allowed to copulate, levels of DA and its metabolites continued to rise in intact males and in castrates that copulated. The DA response to the estrous female could not be attributed to nonsexual social stimuli, since exposure to another male was ineffective. The DA response to copulation could not be attributed primarily to motor activity, since animals running voluntarily in a running wheel did not show significantly increased DA. These and previous data suggest that DA released in the MPOA in response to an estrous female may contribute to sexual motivation and copulatory proficiency. Testosterone may promote copulation in part through permissive actions on dopamine release.
\end{abstract}

[Key words: dopamine, testosterone, medial preoptic area, copulation, sexual motivation, microdialysis, rats]

The occurrence of copulation requires the enhancement of behavioral responsiveness to sexual stimuli and the integration of multiple behavioral elements into a complex, precise pattern. Gonadal steroid hormones upregulate, or prime, the responsivencss of a widespread array of neurons that possess cytoplasmic steroid receptors. In this way, steroid hormones bias sensorimotor processing. so that a sexually relevant stimulus is more likely to elicit a sexual response. The translation of the slow, long-term, and diffuse effects of steroid hormones into a fast,

\footnotetext{
Received Apr. 17. 1995: revised July 3. 1995: accepted July 14, 1995.

This research was supported by NIH Grant MH40826 to E.M.H.

Correspondence should be addressed to Elaine M. Hull, Ph.D., Department of Psychology, Park Hall, State I Iniversity of New York at Buffalo, Buffalo, NY 14260 .

Copyright $\odot 1995$ Society for Neuroscience $\quad 0270-6474 / 95 / 157465-07 \$ 05.00 / 0$
}

precise behavior may occur through their ability to increase (or in some cases, decrease) neurotransmitter synthesis, release, receptors, or second-messenger coupling.

One neurotransmitter system that may be upregulated by hormones is dopamine (DA). DA agonists have long been known to increase the libido and/or sexual potency of males of numerous mammalian species, including humans (reviewed in Bitran and Hull, 1987; Melis and Argiolas, 1995). Furthermore, microinjections of DA agonists into a major regulatory site for male sexual behavior, the medial preoptic area (MPOA), facilitated copulation and ex copula genital reflexes in male rats (Hull et al., 1986, 1992; Pehek et al., 1989). On the other hand, microinjections of DA antagonists (Warner et al., 1991) or 6-OHDA lesions of DA terminals in the MPOA (Bitran et al., 1988: Bazzett et al., 1992) impaired these measures.

Previous reports suggested that DA may be released in the MPOA before and/or during copulation. A chronoamperometric signal in the MPOA increased before and during copulation; however, the specific contribution of DA to the signal could not be determined precisely (Blackburn et al., 1992). In microdialysis studies, the DA metabolites 3,4-dihydroxyphenylacetic acid (DOPAC) and homovanillic acid (HVA) increased during copulation, as did DA itself in some animals; however, DA was below the level of detection for most animals (Hull et al., 1993; Fumero et al., 1994; Mas et al., 1995). Improved high-performance liquid chromatography with electrochemical detection (HPLC-EC) techniques now allow DA to be detected in the MPOA of almost all animals tested.

The current experiments were designed to test: (1) whether extracellular DA increases during a precopulatory period when a receptive female is separated from the male by a perforated Plexiglas barrier and/or during copulation; (2) whether nonsexual social stimuli accounts for the precopulatory DA increase; (3) whether the motor activity of copulation accounts for any DA increase during copulation; and (4) whether the concurrent or recent presence of testosterone is necessary for the DA response to the female or to copulation.

\section{Materials and Methods}

Overview. Four separate experiments were conducted. Experiment 1 tested whether precopulatory exposure 10 an estrous female and/or the act of copulation elicits an increase in extracellular DA and its metabolites in the MPOA. Nine gonadally intact males were exposed to an estrous female across a perforated Plexiglas barrier, after which the barrier was removed and the animals were allowed to copulate. For six of these animals, the precopulatory period, with the female across the barrier, was 12 min (one sample analyzed); for three, it was $60 \mathrm{~min}$ (five samples analyzed). After the barrier was removed, three additional samples were analyzed during copulation. Experiment 2 tested DA responses to nonsexual social stimuli. Seven males were exposed to a stud male across the barrier for $12 \mathrm{~min}$ (one sample analyzed), after 
which the stud male and the barrier were removed, and two postexposure samples were analyzed. Experiment 3 tested whether motor activity could account for increases in DA during copulation. Seven animals were given repeated experience in a running wheel apparatus; four additional animals were repeatedly exposed to the same apparatus, but with the running wheel locked. On the day of testing, all animals could run voluntarily for up to $18 \mathrm{~min}$ (two samples analyzed). Experiment 4 tested whether recent or concurrent testosterone promoted DA responses to an estrous female during the precopulatory or copulatory periods. Seven castrates were given testosterone replacement, while 18 were treated with oil vehicle for 1 or 2 weeks. They were tested under conditions identical to those in Experiment 1 (one precopulatory sample analyzed and three samples analyzed after the barrier was removed).

Subjects. Adult male Long-Evans/Blue Spruce rats $(300$ to $375 \mathrm{gm}$ at the time of testing) were obtained from Harlan Sprague-Dawley (Indianapolis, IN). They were housed individually in large plastic cages. A 14:10 light:dark cycle was in effect, with lights out at $1100 \mathrm{~h}$. Food and water were available ad libitum. Males in Experiments 1 and 4 were given at least three $60 \mathrm{~min}$ sexual experiences with a receptive female and ejaculated at least once during each encounter. In Experiment 1 , nine gonadally intact, sexually experienced males were used to test whether extracellular DA would increase during a precopulatory period and/or during copulation. In Experiment 2, seven sexually naive animals were tested with a stud male, rather than an estrous female, on the other side of the perforated barrier. In Experiment 3 , seven sexually naive animals were given repeated experience in a running wheel; four additional sexually naive animals were exposed repeatedly to the same apparatus, but the wheel was locked. In Experiment 4, 25 animals were castrated and given daily i.p. injections of either $200 \mu \mathrm{g}$ testosterone propionate (TP, Sigma Chemical, St. Louis, MO, $n=7$ ) or olive oil vehicle (Sigma Chemical, $N=18$ ). Of the oil-treated castrates, 14 were tested 1 week postcastration, and 4 were tested 2 weeks after castration. The TP-treated animals were tested 1 week postcastration. All procedures were in accordance with the NIH Guidelines for the Use of Animals.

Surgery. Five to $14 \mathrm{~d}$ before undergoing microdialysis, males were anesthetized with i.m. injections of ketamine hydrochloride $(50 \mathrm{mg} / \mathrm{kg}$ ) and xylazine hydrochloride $(4 \mathrm{mg} / \mathrm{kg})$. A guide cannula, made of 21 ga thin-wall stainless steel was implanted, ending $1 \mathrm{~mm}$ above the MPOA (AP, 2.4; ML, 0.2; DV, -7.0 ; incisor bar, +5.0; Pellegrino et al., 1979). The top half of a $250 \mu \mathrm{l}$ centrifuge tube surrounded the guide cannula, and both were cemented to the skull. The dialysis probe was inserted through and epoxied to the cap of the centrifuge tube, forming a removable probe assembly. The position of the probe in the cap was measured so that the dialysis membrane would extend through the MPOA. A female connector was also embedded in the dental cement; when attached to a male connector on the probe assembly, it prevented movement of the probe during testing. An obturator, cut the same length as the guide cannula, was inserted in the guide cannula until the microdialysis experiment began. After the dental acrylic was hardened around the probe assembly, Bacitracin antibiotic was spread around the wound margins, and the animal was injected with Gentamicin antibiotic $(0.02$ $\mathrm{mg} / \mathrm{kg} /$ day for $3 \mathrm{~d}$ ).

Twenty-five males were castrated while still under anesthesia. A longitudinal midscrotal incision was made, and the testes and surrounding fatty tissue were tied off. A cut was made distal to the ligature, to remove the testes and surrounding tissue; the skin was sutured and spread with Bacitracin ointment. Beginning immediately after surgery and continuing for either 7 or $14 \mathrm{~d}$, animals were injected daily with either $200 \mu \mathrm{g}$ TP or the oil vehicle.

Female rats of the same strain were ovariectomized under ketamine hydrochloride $(50 \mathrm{mg} / \mathrm{kg})$ and $x y l a z i n e$ hydrochloride $(4 \mathrm{mg} / \mathrm{kg})$ anesthesia. They were brought into behavioral estrus with $10 \mu \mathrm{g}$ estradiol benzoate administered s.c. $48 \mathrm{hr}$ before they were to be used as stimulus females. Behavioral receptivity was confirmed by placing them with a stud male shortly before they were to be used in an experiment.

Testing procedures. Animals were briefly anesthetized with an i.p. injection of ketamine hydrochloride $(17 \mathrm{mg} / \mathrm{kg})$ and xylazine hydrochloride $(1.3 \mathrm{mg} / \mathrm{kg})$ prior to probe insertion, after which the flow of dialysate was initiated. Animals for copulation tests were placed into a circular Plexiglas arena (46 cm diameter) with wood chips on the floor Animals used for running wheel tests were placed into a $38 \mathrm{~cm}^{3}$ plywood box, painted white, with a running wheel accessible from one side; entry to the running wheel was blocked during baseline sampling. After at least $2 \mathrm{hr}$, samples were collected every $6 \mathrm{~min}$ and injected

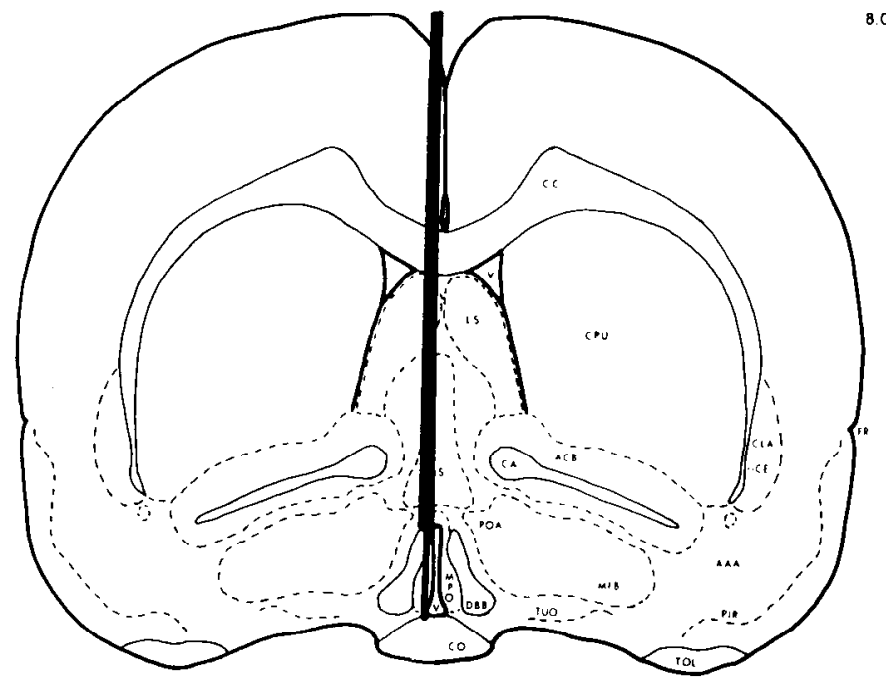

Figure 1. A representative placement of microdialysis probes in these experiments.

onto the analytical column. Because the retention time of serotonin on the column was approximately $12 \mathrm{~min}$, only every other sample was analyzed; the remainder were frozen, in case they were needed. When three consecutive analyzed samples showed less than $10 \%$ variability, the third such sample was taken as the baseline. Because of the extreme variability of absolute DA levels among animals, all data points (including the final baseline) are expressed as a percentage of the average of the last two baseline samples.

Copulation tests. After the baseline criterion was met, a perforated Plexiglas barrier was placed into the arena, dividing it in half. A sexually receptive female was placed into the side opposite the male. The male could see, smell, and hear the female, but could not contact her Two samples were collected, one of which was analyzed, during this precopulatory period. For three intact animals in Experiment 1, the female remained behind the barrier for $60 \mathrm{~min}$, with five samples being analyzed; this procedure tested whether the increase in extracellular DA observed during the precopulatory period would continue to increase, level off, or decline in the absence of copulatory activity. After the precopulatory period, the barrier was removed, and the animals were allowed to copulate for 36 min (three samples analyzed).

Nonsexual social stimuli tests. Seven sexually naive males were tested for DA responses to nonsexual social stimuli. After the baseline criterion was met, a perforated Plexiglas barrier was placed into the arena. A stud male was introduced into the arena across the barrier from the test male. One sample was analyzed during the $12 \mathrm{~min}$ of exposure to the stud male, after which both the stud male and the barrier were removed, and two final samples were analyzed.

Running wheel tests. In order to determine whether the motor activity of copulation was a major factor in any DA release, 11 sexually naive males were tested in a running wheel apparatus. Seven had received daily running wheel experience for 5 weeks, $4 \mathrm{hr} / \mathrm{day}$, before undergoing microdialysis; the remaining four spent the same amount of time in the apparatus, but with the wheel secured, so that it would not turn. On the day of microdialysis testing, the animal was placed into the box, with a barrier blocking the entry to the running wheel. Baseline samples were collected while the male was in the box. The barrier was then lifted, and the male was allowed to run freely in the wheel; wheel revolutions were automatically counted. Two samples were analyzed during the $18 \mathrm{~min}$ period of wheel access.

Microdialysis procedures. Concentric microdialysis probes were constructed according to the procedure of Yamamoto and Pehek (1990). The dialysis membrane (Spectrum. Houston, TX) had an o.d. of 210 $\mu \mathrm{m}$, an active dialyzing length of $1 \mathrm{~mm}$, and a $6000 \mathrm{MW}$ cutoff. A teflon-covered tether encased the inflow tubing. Dulbecco's phosphate buffered saline (Sigma Chemical, St. Louis, MO) (138 mM NaCl, 2.7 $\mathrm{mM} \mathrm{KCl}, 0.5 \mathrm{~mm} \mathrm{MgCl}, 1.5 \mathrm{mM} \mathrm{KH}_{2} \mathrm{PO}_{4}, 1.2 \mathrm{mM} \mathrm{CaCl}, \mathrm{pH} 6.5$, filtered and degassed prior to use) was perfused at a rate of $0.5 \mu \mathrm{l} / \mathrm{min}$ with a Harvard model \#22 infusion pump, using a $1 \mathrm{ml}$ gastight syringe. Samples were collected every $6 \mathrm{~min}$ and assayed immediately using HPLC-EC. Dopamine from only the immediate vicinity of the mem- 
brane can diffuse into the probc, bccause of rapid uptake into terminals; DOPAC, however, may diffuse as far as $0.35 \mathrm{~mm}$ under certain conditions (Parsons and Justice, 1994).

Chromatography. The LC Packings (San Francisco, CA) chromlatographic system consisted of an Accurate microflow processor and pulsedamper, a Rheodyne injector with a $500 \mathrm{nl}$ sample loop, and an Antec micro electrochemical detector equipped with a microflow cell (1) $\mathrm{nl}$ cell volume), with a glassy carbon working electrode and a $\mathrm{Ag} / \mathrm{AgCl}$ reference electrode. The analytical column was an LC Packings Fusica reversed-phase capillary column $(320 \mu \mathrm{m}$ i.d., $5 \mathrm{~cm}$ long, packed with $3 \mu \mathrm{m}$ C- 18 particles). The working electrode was maintained at an applied potential of $+0.7 \mathrm{~V}$ relative to the reference electrode. A Gilson model 307 pump delivered mobile phase through the system at 0.62 $\mathrm{ml} / \mathrm{min}$; however, the Accurate microflow processor split the flow, so that flow through the analytical column was approximately $8 \mu \mathrm{l} / \mathrm{min}$. The mobile phase consisted of $32 \mathrm{~mm}$ citric acid, $54.3 \mathrm{~mm}$ sodium acetate, $0.074 \mathrm{~mm} \mathrm{Na}$ EDTA, $0.215 \mathrm{~mm}$ OSA, 3\% methanol (V/V), and $0.004 \%$ tetrahydrofuran. It was filtered and degassed under vacuum; $\mathrm{pH}$ was 3.8. Data were collected using a Gateway 2000486 microcomputer workstation running Gilson 715 HPLC system controller software, which also controlled the pump parameters.

Histology. After each experiment, probe placements were verified histologically. The animal was deeply anesthetized with pentobarbital, and Evans blue stain was perfused through the probe. After decapitation of the animal, the brain was removed, frozen, and cut with a Cryocut microtome into $40 \mu \mathrm{m}$ slices, which were dry mounted onto slides. Sections were examined with a projection magnifier. Data from animals with probes located outside the MPOA were not included in statistical analysis. Two testostcrone-treated castrates had probes located posterior and dorsal to the MPOA; their data were averaged and summarized in Results, but could not be analyzed statistically. A diagram depicting a representative probe placement is shown in Figure 1.

Statistics. Data from Experiments 1 and 4 were combined for statistical analysis and for presentation in figures. Chromatographic data (area under the curve for DA, DOPAC, and HVA) from five samples from each animal (last baseline, first precopulation, first, third, and fifth copulation samples) were subjected to two-factor (hormone condition and sample number) repeated measures analyses of variance. Because all main effects and interactions in the two-factor analyses were significant $(p<0.01)$, one-way repeated measures analyses of variance were used for each hormone condition, followed by Newman-Keuls post hoc comparisons. $F$-Values for the one-way analyses are presented in Results. For onc of the 1-weck oil-treated castrates, D $\Lambda$ levels were below the detection threshold; therefore, only his DOPAC and HVA data could be analyzed. Data from Experiment 2 were analyzed using one-way repeated measures analyses of variance comparing the last two baselint samples, the sample during exposure to the stud male, and the two postmale samples. For Experiment 3, a two-factor repeated measures analysis of variance compared previous running wheel experience and sample number (final baseline, first, and third run samples). A $t$ test was used to compare numbers of wheel revolutions during the microdialysis test for animals experienced in the running wheel versus those with no running experience.

\section{Results}

Experiment 1. Gonadally intact males

During the precopulatory period, gonadally intact males showed an increase in extracellular DA $[F(4,32)=5.00, p<0.01$, Fig. $2 A]$ and HVA $[F(4,32)=9.53, p<0.001$, Fig. $2 C]$. During this period, all males exhibited considerable interest in the female, sniffing through the perforations in the barrier; some also exhibited ex copula erections. In all intact animals, DA levels during the precopulatory period were higher than in the preceding baseline sample. Levels of DA and its metabolites increased further in the three copulation samples; the increase in DOPAC levels achieved statistical significance only during copulation [DOPAC: $F(4,32)=3.77, p<0.025$, Fig. $2 B]$. All animals copulated, achieving an ejaculation within the first $6 \mathrm{~min}$ sample period. For three of the nine animals, the precopulatory period was extended to $60 \mathrm{~min}$. DA levels rose initially, and then gradually fell to near baseline levels (Fig. $3 A$ ). However, when the banrier was removed, levels increased comparably to animals with shorter precopulatory periods. Because these animals showed the same pattern of results in the first precopulatory sample and the three copulation samples as did the animals with shorter precopulatory periods, data from all nine animals were combined for those samples.

\section{Experiment 2. Nonsexual social stimuli tests}

There were only small, statistically nonsignificant differences in levels of DA or its metabolites in response to the stud male. DA levels before, during, and after exposure to the stud male are presented in Figure $3 B$.

\section{Experiment 3. Running wheel tests}

There were no differences between animals with previous running experience, compared to those with no running experience; therefore, their data were combined for statistical purposes. There were slight, nonsignificant increases in DA and its metabolites during the running wheel experiments. DA levels before and during running are presented in Figure $3 C$. The total number of wheel revolutions during the two sample periods was slightly, but not :ignificantly, greater in males with running experience [experienced: $78.3 \pm 18.7$; inexperienced: $53.5 \pm 5.6 ; t(9)=$ $0.97]$.

\section{Effects of testosterone}

Castrates treated with $200 \mu \mathrm{g} \mathrm{TP}$ showed an increase in extracellular DA during the precopulatory period $[F(4,30)=3.51, p$ $<0.02$, Fig. 2A]. DA metabolites rose during copulation [DOPAC: $F(4,30)=7.71, p<0.001$, Fig. $2 B$; HVA: $F(4,30)=$ $3.53, p<0.02$, Fig. $2 C$ ]. TP-treated castrates showed interest in the female across the barrier, as had the gonadally intact males, and all copulated after the barrier was removed.

None of the 2-week oil-treated castrates showed an increase in DA or its metabolites at any time, and none copulated. Five of the 14 1-week castrates failed to copulate; they, too, showed no increases in DA or its metabolites at any time. Because their levels were not different from the 2-week castrates, their data were combined for graphical and statistical purposes (Fig. 2). Nine of the oil-treated 1-week castrates did copulate; their levels of DA and its metabolites increased comparably to intact animals [DA: $F(4,35)=3.46, p<0.02$, Fig. $2 A$; DOPAC: $F(4,40)$ $=10.2, p<0.001$, Fig. $2 B$; HVA: $F(4,40)=6.99, p<0.001$, Fig. $2 C$ ]. In all animals that subsequently copulated, DA levels during the precopulatory period were higher than the preceding baseline.

Two testosterone-treated castrates had probes located dorsal and posterior to the MPOA. Their DA levels declined steadily throughout the experiment, from $91 \%$ (final baseline) to $71 \%$ (last copulation sample). DOPAC levels rose slightly from $98 \%$ (final baseline) to $109 \%$ (last copulation sample), and HVA levels rose from $97 \%$ (final baseline) to $105 \%$ (last copulation sample). No other animals that copulated had misplaced probes.

\section{Discussion}

These experiments show a consistent relationship between a rise in extracellular DA in the MPOA during the precopulatory period and the animal's subsequent copulatory behavior. That is, every animal that showed at least some increase in DA during the precopulatory period also copulated after the barrier was removed, and no animal copulated that had failed to show such a precopulatory rise. This suggests that DA in the MPOA may 

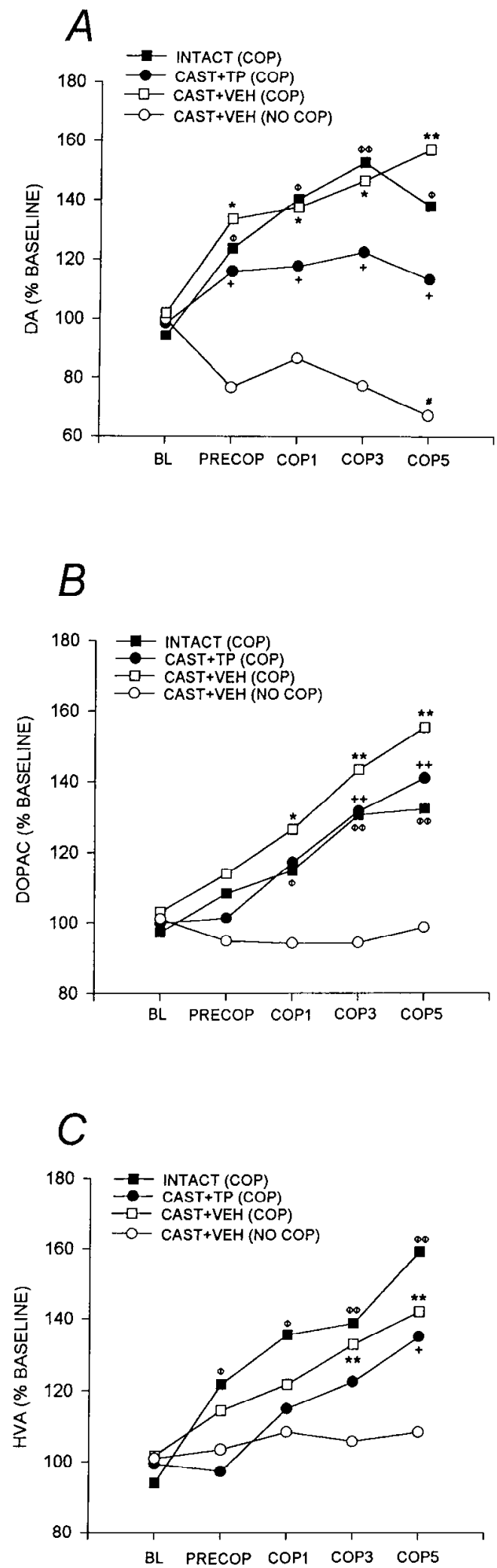

Figure 2. Extracellular levels of MPOA dopamine (DA) and its metabolites (DOPAC and HVA) during a precopulatory period, during which an estrous female was separated from the male by a perforated barrier, and during three copulatory intervals, when the female was freely accessible. Each value represents the mean dialysate concentration, presented as percentage of baseline. $A$, Extracellular DA in the MPOA. DA levels rose during the precopulatory period in all animals that subsequently copulated $(C O P)$, including all nine intact males, all seven castrates treated with $200 \mu \mathrm{g} /$ day testosterone propionate, and be extremely important for enhancing the responsiveness of output neurons to sexually relevant stimuli. In the striatum, DA appears to increase the activity of a select group of output neurons primarily through disinhibition (Chevalier and Denau, 1990). It is possible that DA may perform a functionally similar role in the MPOA.

The rise in DA during the precopulatory period provides strong support for the suggestion that MPOA DA contributes to sexual motivation, as well as to copulatory performance (Pfaus and Phillips, 1991; Warner et al., 1991; Blackburn et al., 1992; Moses et al., 1995). DA levels did not rise significantly during similar exposure to a stud male, suggesting that the DA response to the estrous female was not the result of nonsexual social stimuli. It has been suggested previously that the MPOA contributes almost exclusively to sexual performance, whereas the mesolimbic system provides the motivational impetus (Everitt, 1990). However, blocking DA receptors in the MPOA has previously led to decreases in at least two measures of sexual motivation. We have shown that the DA antagonist cis-flupenthixol, microinjected into the MPOA, decreased the percentage of X-maze trials in which the male chose the female's goal box (Warner et al., 1991). In addition, the DA antagonist haloperidol, microinjected into the MPOA, decreased the male's attempts to find an estrous female in a bilevel apparatus (Pfaus and Phillips, 1991). Furthermore, electrolytic lesions of the MPOA decreased the preference of a male for an estrous female (Edwards and Einhorn, 1986) and decreased the male's pursuit of an estrous female (Paredes et al., 1993). In castrated mice, MPOA implants of testosterone restored several measures of sexual motivation. even though little mounting was observed (Matochik et al., 1994). Additional support for the motivational role of the MPOA is found in a study of single cell activity before and during copulation (Shimura et al., 1994). Some MPOA neurons showed increased responding while the male was actively sniffing and pursuing the receptive femalc, while others became active only during mounts, intromissions, or ejaculations. Thus, neural activity in the MPOA, and DA released there, may contribute hoth to sexual motivation and to copulatory performance.

The additional increase in levels of DA and its metabolites during copulation did not represent a simple continuation of the precopulatory rise. When the precopulatory period was in-

$\leftarrow$

nine 1-week castrates treated with oil vehicle. DA levels increased slightly more during copulation in the intact males and vehicle treated castrates that copulated. DA levels fell in all animals that failed to copulate $(N O C O P)$, including the remaining five 1 -week castrates and all four 2 -week castrates treated with vehicle. Statistical values are presented in Results. $B$, Extracellular DOPAC in the MPOA. DOPAC levels increased significantly during copulation in all animals that copulated $(C O P)$, but did not increase in animals that failed to copulate (NO COP). Statistical values are presented in Results. $C$. HVA levels in the MPOA. HVA levels increased during the precopulatory period in intact animals, and during copulation in all animals that copulated $(C O P)$. HVA levels did not increase at any time in those vehicle-treated castrates that failed to copulate (NOCOP). Statistical values are presented in Results. $\varnothing, p<0.05$ compared to final baseline for intact males; $\varnothing \varnothing$. $p<0.01$ compared to final baseline for intact males; $+. p<0.05$ compared to final baseline for castrates treated with $200 \mu \mathrm{g}$ testosterone propionatc;,$++ p<0.01$ comparcd to final baseline for castrates treated with $200 \mu \mathrm{g}$ testosterone propionate; ${ }^{*} p<0.05$ compared to final baseline for 1 -week vehicle-treated castrates that copulated; ${ }^{* *} p<0.01$ compared to final baseline for 1 -week vehicle-treated castrates that copulated; \#, $p<0.05$ compared to final baseline for vehicle-treated castrates that failed to copulate. 

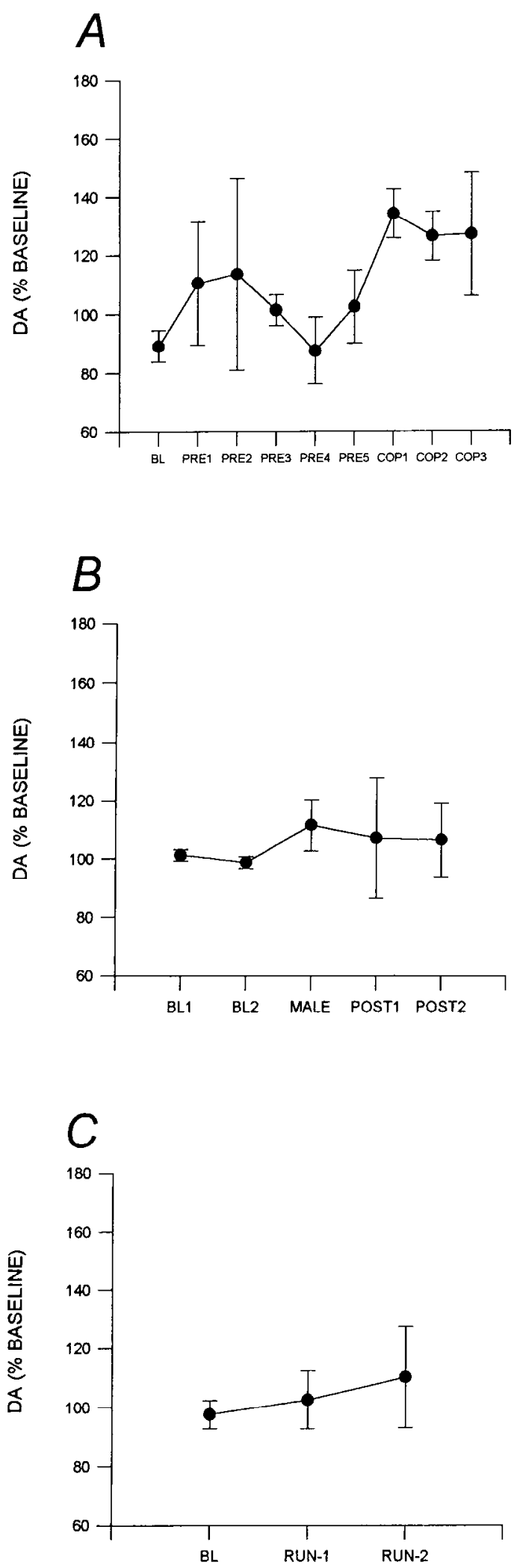

Figure 3. Extracellular levels of MPOA DA during a $60 \mathrm{~min}$ precopulatory exposure to an estrous female, during exposure to a stud male, and during voluntary running in a running wheel. Each value represents the mean dialysate concentration, presented as percentage of baseline. $A$, Extracellular DA from three intact males during a $60 \mathrm{~min}$ precopulatory exposure to an estrous female behind a perforated Plexiglas barricr and during copulation, after the barrier was removed. Responses during the first precopulatory sample and the three copulation samples were similar to those of six other intact males that had shorter preco- creased to 60 min, there was the usual initial rise in DA levels, correlated with intense sniffing through the perforations in the barrier. However, it was followed by a gradual decline, during which the male frequently sat in the arena or walked around, rather than sniffing through the perforations. After the barrier was removed, levels of DA and its metabolites immediately increased, as the animals began to copulate. Therefore, the increase in DA activity during copulation was tied to the behavior itself, rather than simple passage of time in the presence of the female.

The increase in DA during copulation also appeared not to result primarily from motor activity. During the $18 \mathrm{~min}$ period of wheel running, there was only a slight, nonsignificant, increase in DA activity. Hoffman et al. (1987) reported that $e x$ vivo tissue levels of DA in the MPOA were increased similarly in animals that had copulated to exhaustion and in "motor controls" that had been forced to run on a treadmill for a similar length of time. However, the amount of motor activity involved in forced running is considerably greater than that required for copulation. Indeed, the male spends much of the time in a copulation test sitting or lying down, especially during the postejaculatory interval, which may account for half the test period. In addition, males forced to run in order to avoid shock have an additional stressor imposed that is not at all characteristic of a copulation test. Therefore, we chose a motor control condition that allowed the male to determine the amount and timing of his activity. All motor control animals ran voluntarily, with an average of 35 revolutions during each of the two 6 min sample periods. The lack of a significant rise in DA or its metabolites during the running activity suggests that the increases that were observed in the precopulatory and copulatory periods did not result from enhanced motor activity.

Similar behavioral specificity was observed in a previous ex periment, in which DA metabolites increased in the MPOA during copulation, but not when the animal ate a highly palatable food (Hull et al., 1993). This specificity of DA response in the MPOA is in contrast with the effectiveness of a wide variety of stimuli and behaviors, including voluntary locomotor activity, in eliciting DA release in the nucleus accumbens (Mogenson et al., 1980; Spyraki et al., 1983; Stellar et al., 1983; Wise and Bozarth, 1984; Mucha and Iversen, 1986; Fibiger and Phillips, 1988; Sabol et al., 1989; Mark et al., 1991). There may not be complete behavioral specificity of the DA response in the MPOA, however, since this area has also been implicated in maternal behavior (Numan, 1986) and temperature regulation (Satinoff et al., 1982).

A permissive effect of concurrent or recent testosterone may be necessary for the DA release in response to a receptive female. The only animals that failed to copulate in these experiments were vehicle-treated 1 - or 2-week castrates. However, more than half the 1-week castrates did show a precopulatory DA response and did copulate. Because testosterone levels and androgen receptors decline rapidly after castration (Krey and

$\leftarrow$

pulatory intervals; their data from those samples were combined for statistical purposes. $B$, Extracellular DA from seven males during a 12 min exposure to a stud male behind a perforated Plexiglas barrier and for two samples after the male and the barrier were removed. DA did not increase significantly. $C$, Extracellular DA from eleven males during $18 \mathrm{~min}$ of voluntary running in a running wheel. DA did not increase significantly. 
McGinnis, 1990), it is unlikely that the 1 -week vehicle-treated castrates had measurable serum testosterone levels. Since more than half of these animals showed the DA response to the female and were able to copulate, it would seem that the concurrent presence of testosterone is not required for these effects. However, since all of the 2-week castrates, and the remainder of the l-week castrates, failed to show the DA response and failed to copulate, recent testosterone exposure may be needed to produce relatively long-lasting permissive effects. Indeed, both the onset and the offset of testosterone's behavioral effects are slow. Longterm castrates that begin a regimen of exogenous testosterone typically begin to copulate about 10 to $14 \mathrm{~d}$ after the onset of the treatment (McGinnis et al., 1989). Similarly, the loss of copulation after castration occurs over a 1 to 4 week period for most animals (Davidson, 1966). It appears that the MPOA DA response to an estrous female is lost concurrently with the ability to copulate.

Castration also affects electrophysiological responses of MPOA neurons. In gonadally intact males, the odor of a receptive female altered firing rates of neurons in both the olfactory bulb and the MPOA (Pfaff and Pfaffman, 1969). However, in animals castrated at least 2 weeks previously, MPOA neurons were unresponsive, even though olfactory bulb neurons responded normally. Therefore, neurons in a site critical for male sexual behavior depend on testosterone to maintain their responsiveness to a sexually relevant stimulus.

In summary, we have observed a consistent relationship between an increase in extracellular DA in the MPOA during a precopulatory period and the subsequent copulatory behavior of the animals. Extracellular DA did not increase significantly when a stud male was present across the barrier, suggesting that nonsexual social stimuli contributed little to the increase observed with the estrous female. This lends credence to our previous suggestion that MPOA DA contributes to sexual motivation, as well as to copulatory performance (Warner et al., 1991; Hull, 1995). In addition, we have shown that locomotor activity in cxecss of that usually cxhibited during copulation did not elicit a significant increase in extracellular DA in the MPOA. The lack of DA increases during wheel running in this experiment, or eating a highly palatable food in a previous experiment (Hull et al., 1993), indicates at least some behavioral specificity of this response. Finally, the DA response to a receptive female, as well as the ability to copulate, appear to depend on the recent presence of testosterone. However, the mechanism by which testosterone promotes the DA response is not clear.

\section{References}

Bazzell TJ, Lumley LA, Bitran D, Markowski VP, Warner RK, Hull EM (1992) 6-OHDA lesions of MPOA impair copulation in male rats. Brain Res 580:164-171.

Bitran D, Hull EM (1987) Pharmacological analysis of male rat sexual behavior. Neurosci Biobehav Rev 11:365-389.

Bitran D, Hull EM, Holmes GM, Lookingland KJ (1988) Regulation of male rat copulatory behavior by preoptic incertohypothalamic dopamine neurons. Brain Res Bull 20:323-331.

Blackburn JR, Pfaus JG, Phillips AG (1992) Dopamine functions in appetitive and defensive behaviours. Prog Neurobiol 39:247-279.

Chevalier G, Denau JM (1990) Disinhibition as a basic process in the expression of striatal functions. Trends Neurosci 13:277-280.

Davidson JM (1966) Characteristics of sex behaviour in male rats following castration. Anim Behav 14:266-272.

Edwards DA, Einhorn LC (1986) Preoptic and midbrain control of sexual motivation. Physiol Behav 37:329-335.

Everitt BJ (1990) Sexual motivation: a neural and behavioural analysis of the mechanisms underlying appetitive and copulatory responses of male rats. Neurosci Biobehav Rev 14:217-232.

Fibiger HC, Phillips AG (1988) Mesocorticolimbic dopamine systems and reward. In: The mesocorticolimbic dopamine system, Vol 537 (Kalivas PW, Nemeroff CB, eds), pp 206-215. New York: New York Academy of Science.

Fumero B, Fernandez-Vera JR, Gonzalez-Mora JL, Mas M (1994) Changes in monoamine turnover in forebrain areas associated with sexual behavior: a microdialysis study. Brain Res 602:233-239.

Hoffman NW, Gerall AA, Kalivas PW (1987) Sexual refractoriness and locomotion effects on brain monoamines in the male rat. Physiol Behav 41:563-569.

Hull EM (1995) Dopaminergic influences on male rat sexual behavior. In: Neurobiological effects of sex steroid hormones (Micevych PE, Hammer R, eds), pp 234-253. Cambridge: Cambridge UP.

Hull EM, Bitran D, Pehek EA, Warner RK, Band LC. Holmes GM (1986) Dopaminergic control of male sex behavior in rats: effects of an intracerebrally infused agonist. Brain Res 370:73-81.

Hull EM, Eaton RC, Markowski VP, Moses J, Lumley LA, Loucks, JA (1992) Opposite influence of medial prcoptic $D_{1}$ and $D_{2}$ receptors on genital reflexes: implications for copulation. Life Sci 51:1705-1713.

Hull EM, Eaton RC, Moses J, Lorrain DS (1993) Copulation increases dopamine activity in the medial preoptic area of male rats. Life Sci 52:935-940.

Krey LC, McGinnis MY (1990) Time-courses of the appearance/disappearance of nuclear androgen + receptor complexes in the brain and adenohypophysis following testosterone administration/withdrawal to castrated male rats: relationships with gonadotropin secretion. J Steroid Biochem 35:403-408.

Mark GP, Schwartz DH, Hernandez L, West HL, Hoebel BG (1991) Application of microdialysis to the study of motivation and conditioning: measurements of dopamine and serotonin in freely behaving rats. In: Techniques in the behavioral and neural sciences, $V_{0} 7$, Microdialysis in the neurosciences (Robinson TE, Justice JB Jr, eds), pp 369-388. New York: Elsevier.

Mas M, Fumero B, Fernandez-Vera JR, Gonzalez-Mora, JL (1995) Neurochemical correlates of sexual exhaustion and recovery as assessed by in vivo microdialysis. Brain Res 675:13-19.

Matochik JA, Sipos ML, Nyby JG, Barfield RJ (1994) Intracranial androgenic activation of male-typical behaviors in house mice: motivation versus performance. Behav Brain Res 60:141-149.

McGinnis MY, Mirth MC, Zebrowski AF, Dreifuss RM (1989) Critical exposure time for androgen activation of male sexual behavior in rats. Physiol Behav 46:159-165.

Melis MR, Argiolas A (1995) Dopamine and sexual behavior. Neurosci Biobehav Rev 19:19-38.

Mogenson GJ, Jones DL, Yim CY (1980) From motivation to action: functional interface between the limbic system and the motor system. Prog Neurobiol 14:69-97.

Moses J, Loucks JA, Watson HL, Matuszewich L, Hull EM (1995) Dopaminergic drugs in the medial preoptic area and nucleus accumbens: effects on motor activity, sexual motivation and sexual performance. Pharmacol Biochem Behav 51:681-686.

Mucha RF, Iversen SD (1986) Increased food intake after opioid microinjections into nucleus accumbens and ventral tegmental area of rat. Brain Res 397:214-224.

Numan M (1986) The role of the medial preoptic area in the regulation of maternal behavior in the rat. In: Reproduction: a behavioral and neuroendocrine perspective, Vol 474 (Komisaruk B, Siegel HI. Cheng M-F, Feder HH, eds), pp 226-233. New York: New York Academy of Science.

Paredes RG, Highland L, Karam P (1993) Socio-sexual behavior in male rats after lesions of the medial preoptic area: evidence for reduced sexual motivation. Brain Res 618:271-276.

Parsons LH, Justice JB Jr (1994) Quantitative approaches to in vivo brain microdialysis. Crit Rev Neurobiol 8:189-220.

Pehek EA, Thompson JT, Hull EM (1989) The effects of intracranial administration of the dopamine agonist apomorphine on penile reflexes and seminal emission in the rat. Brain Res 500:325-332.

Pellegrino LJ, Pellegrino AS, Cushman AJ (1979) A stereotaxic atlats of the rat brain, 2nd ed. New York: Plenum.

Pfaff DW, Pfaffman C (1969) Olfactory and hormonal influences on the basal forebrain of the male rat. Brain Res 15:137-158.

Pfaus JG, Phillips AG (1991) Role of dopamine in the dorsal and ventral striatum. Semin Neurosci 4:119-128. 
Sabol KE, Kichards JB, Freed CK (1989) In vivo dialysis measurements of dopamine and DOPAC in rats trained to turn on a circular treadmill. Pharmacol Biochem Behav 36:21-28.

Satinoff E, Liran J, Clapman R (1982) Aberrations of circadian body temperature rhythms in rats with medial preoptic lesions. Am J Physiol 242:R352-R357.

Shimura T, Yamamoto T, Shimokochi M (1994) The medial preoptic area is involved in both sexual arousal and performance in male rats: reevaluation of neuron activity in frecly moving animals. Brain Res $640: 215-222$

Spyraki C, Fibiger HC, Phillips AG (1983) Attenuation of heroin reward in rats by disruption of the mesolimbic dopamine system. Psychopharmacology (Berlin) 79:278-283.
Stellar JR, Kelley A, Corbett D (1983) Etfects of peripheral and central dopamine blockade on lateral hypothalamic self-stimulation: evidence for both reward and motor deficits. Pharmacol Biochem Behav $18: 433-442$

Warner RK, Thompson JT, Markowski VP, Loucks JA, Barzett TJ, Eaton RC., Hull EM (1991) Microinjection of the dopamine antagonist cis-flupenthixol into the MPOA impairs copulation. penile reflexes and sexual motivation in male rats. Brain Res 540:177-182.

Wise RA, Bozarth MA (1984) Brain reward circuitry: four elements "wired" in apparent series. Brain Res Bull 12:203-208.

Yamamoto BL, Pehek EA (1990) A neurochemical heterogeneity of the rat striatum as measured by in vivo electrochemistry and microdialysis. Brain Res 506:236-242. 